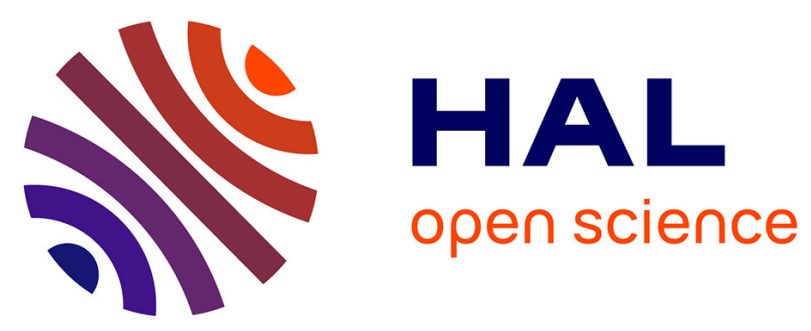

\title{
Design of an Intercalated Nano-MoS 2 Hydrophobic Catalyst with High Rim Sites to Improve the Hydrogenation Selectivity in Hydrodesulfurization Reaction
}

Kun Sun, Hailing Guo, Feng Jiao, Yongming Chai, Yanpeng Li, Bin Liu, Svetlana Mintova, Chenguang Liu

\section{To cite this version:}

Kun Sun, Hailing Guo, Feng Jiao, Yongming Chai, Yanpeng Li, et al.. Design of an Intercalated Nano-MoS 2 Hydrophobic Catalyst with High Rim Sites to Improve the Hydrogenation Selectivity in Hydrodesulfurization Reaction. Applied Catalysis B: Environmental, 2021, 286, pp.119907. 10.1016/j.apcatb.2021.119907 . hal-03145248

\author{
HAL Id: hal-03145248 \\ https://hal.science/hal-03145248
}

Submitted on 18 Feb 2021

HAL is a multi-disciplinary open access archive for the deposit and dissemination of scientific research documents, whether they are published or not. The documents may come from teaching and research institutions in France or abroad, or from public or private research centers.
L'archive ouverte pluridisciplinaire $\mathbf{H A L}$, est destinée au dépôt et à la diffusion de documents scientifiques de niveau recherche, publiés ou non, émanant des établissements d'enseignement et de recherche français ou étrangers, des laboratoires publics ou privés. 
Design of an Intercalated Nano-MoS 2 Hydrophobic Catalyst with High Rim Sites to Improve the Hydrogenation Selectivity in Hydrodesulfurization Reaction

Kun Sun ${ }^{\text {a }}$, Hailing Guo ${ }^{\text {a* }}$, Feng Jiao ${ }^{\text {a, }}$, Yongming Chai ${ }^{\text {a* }}$, Yanpeng Li $^{\text {a }}$, Bin Liu ${ }^{a}$, Svetlana Mintova ${ }^{\mathrm{a}, \mathrm{b}}$, Chenguang Liu ${ }^{\mathrm{a}}$

${ }^{a}$ State Key Laboratory of Heavy Oil Processing, Key Laboratory of Catalysis, China National Petroleum Corp. (CNPC), China University of Petroleum (East China),

Qingdao 266555, PR China

${ }^{\mathrm{b}}$ Normandie University, CNRS, ENSICAEN, UNICAEN, Laboratoire Catalyse et Spectrochimie

E-mail: guohl@upc.edu.cn,ymchai@upc.edu.cn 


\begin{abstract}
The preparation of the intercalated lamellar hydrophobic nano-MoS 2 (size: 60-100 $\mathrm{nm}$, interlayer spacing: $0.7-1.2 \mathrm{~nm}$ ) through the substitution of organic amine for inorganic ammonium salt and the subsequent catalytic reaction as a hydrodesulfurization catalyst is presented. The intercalated amine groups broadened the interspacing of the lamellar nano-MoS 2 and promoted the formation of hydrophobic stacking structure consisting of stable monolayers. The high hydrophobicity of the nano-MoS 2 monolayer catalyst was confirmed. The as-synthesized intercalated hydrophobic nano-MoS $\mathrm{S}_{2}$ catalyst with lower steric hindrance and higher number of rim sites showed better hydrodesulfurization performance and higher hydrogenation route selectivity than the traditional $\mathrm{MoS}_{2}$ catalyst. The conversion of dibenzothiophene using the intercalated hydrophobic nano- $\mathrm{MoS}_{2}$ catalyst was $86 \%$ in comparison to $23 \%$ for the traditional $\mathrm{MoS}_{2}$ catalyst. The intercalated hydrophobic nano- $\mathrm{MoS}_{2}$ catalyst was stable in five subsequent catalytic cycles.
\end{abstract}

Keywords: Ammonium exchange, intercalation method, hydrophobic, monolayer, pathway selectivity 


\section{Introduction}

With the deterioration quality of crude oil and the increase of the number of refractory compounds in oil, a higher hydrogenation selectivity is more important in both parallel reaction paths, i.e. hydrogenation (HYD) and direct desulphurization (DDS) of hydrodesulfurization (HDS) [1-8]. In addition, for compounds with large steric hindrance, such as alkyl-substituted dibenzothiophene (4, 6-DMDBT), the HYD pathway is more appropriate and beneficial for ultra-deep desulfurization $[9,10]$.

In view of the new requirements for hydrogenation, researchers have gradually explored different possibilities to regulate hydrogenation selectivity. It was found that the HYD/DDS selectivity of $\mathrm{MoS}_{2}$ is the best, due to its short slabs and lower average number of $\mathrm{MoS}_{2}$ layers [11, 12]. Alonso et al. [13] and Huirache-Acuña et al. [14] tested the HDS catalytic performance of $\mathrm{WS}_{2}$ and NiMoW catalysts, and observed that the highest hydrogenation selectivity were only 1.4 and 1.14 , respectively. In addition, Nikulshin et al. found that the hydrogenation selectivity in the HDS of alkyl-substituted DBT over a traditional CoMoS catalyst reached 3.1 [15]. At present, the HDS path is controlled by adjusting the catalyst' size or by doping with other metals to improve the hydrogenation pathway selectivity, however, there is still a great need of better performing catalysts.

Relevant studies were dedicated on the specific position of active sites and understanding the relationship of hydrogenation and desulfurization pathways. Daage and Chianelli proposed the "rim-edge" model [16], considering that the rim sites (top and bottom layers) of the $\mathrm{MoS}_{2}$ stack can both carry out HYD and DDS, while the edge sites (middle layers of the stack) mainly prefers the DDS. The discussion on the HDS pathway selectivity (HYD/DDS) of the S-edge and Mo-edge is not in full agreement by various researchers. Density functional theory (DFT) calculations of Zheng et al. 
showed that the Mo-edge (50\% S coverage) was more active for the DDS, while the HYD route mainly occurred at the S-edge (100\% S coverage) [17]. In contrast, Moses et al. believe that the HYD occurred on the Mo-edge, and that the $\mathrm{S}-\mathrm{C}$ bond breaking in the DDS has different proportions at different edges, depending on the relative pressure of $\mathrm{H}_{2}$ and $\mathrm{H}_{2} \mathrm{~S}$ during the HDS reaction [18]. In addition, Lauritsen et al. found that both the brim sites (metallic edges) and S-H groups were closely related to the HYD reaction as shown by scanning tunneling microscopy. At the same time, it was reported that the $\mathrm{MoS}_{2}$ layer at the top of the stacks has accessible brim sites, which could be active for HYD. Moreover, at vacancies in the top layer, the exposed active sites are mainly active in the direct HDS $[19,20]$. This highlights that rim sites of $\mathrm{MoS}_{2}$ (through monolayer $\mathrm{MoS}_{2}$, eliminating the edge side, and leaving the rim sites only) are critical for further analyzing the active sites pathway selectivity in HDS and obtaining catalysts with high HYD selectivity. Thus designing of a single layer $\mathrm{MoS}_{2}$ catalyst (monolayer $\mathrm{MoS}_{2}$ or intercalated $\mathrm{MoS}_{2}$ with wide layer spacing) deserves more attention.

Monolayer nano- $\mathrm{MoS}_{2}$ is usually prepared by the hydrothermal method, chemical vapor deposition (CVD), bulk exfoliation, electrochemical deposition and by the reaction of $\mathrm{MoO}_{\mathrm{X}}$ with $\mathrm{H}_{2} \mathrm{~S}$ at high temperature [21-24]. Because of the low structure stability, hydrophilicity and complex synthesis of the $\mathrm{MoS}_{2}$ according to the above methods, a new synthesis approach for single layer $\mathrm{MoS}_{2}$ is needed to design a highly active hydrodesulfurization catalyst. In 1979, Kikuchi et al. synthesized a lamellar compound that graphite (LCG) intercalated by ferric chloride in flowing $\mathrm{H}_{2}$ at $400{ }^{\circ} \mathrm{C}$, and the LCG catalyst helped hydrocarbons to possess outstanding selectivity [25]. Goni et al. reported on the intercalation using five alkyl amines to form a new layered $\mathrm{HNiPO}_{4} \cdot \mathrm{H}_{2} \mathrm{O}$ catalyst [26]. Tsujimura et al. synthesized a layered 
double hydroxide hydrotalcite-like compound intercalated with chloride ions ( $\mathrm{HT}-\mathrm{Cl})$ using a co-precipitation reaction [27].

Herein, we present the synthesis of lamellar hydrophobic nano- $\mathrm{MoS}_{2}$ intercalated by substitution of organic amine for inorganic ammonium salt and subsequent catalytic reduction. The amine groups formed during the synthesis have three functions: (1) broaden the interspacing of $\mathrm{MoS}_{2}$, (2) produce highly hydrophobic $\mathrm{MoS}_{2}$, and (3) stabilize the final wide interlayer spacing structure (monolayer). Moreover, compared to the traditional hydrothermally-synthesized $\mathrm{MoS}_{2}$ catalyst, the novel nano-MoS intercalated catalyst due to its high hydrophobicity and high proportion of rim sites showed superior hydrogenation selectivity in the HDS reaction.

\section{Experimental}

\subsection{Materials}

Thiourea (AR, 99\%), cyclohexylamine (AR, 99\%), ethanol absolute (AR, 99.7\%), ammonia solution (AR, 25\%-48\%), aniline (AR, 99.5\%), ammonium molybdate tetrahydrate (AR, 99\%), ethylenediamine (AR, 99\%) and ammonium sulfide solution (AR), methylcyclohexane (AR, 99\%), methylbenzene (AR, 99\%), thiophene (AR, 99\%), toluene (AR, 99\%) and heptane (AR, 99\%) were purchased from Sinopharm chemical reagent Co., Ltd. China. Deionized water was home made.

\subsection{Synthesis}

\subsubsection{Preparation of ammonium tetrathiomolybdate (ATTM)}

Firstly, ammonia, ammonium sulfide and ammonium molybdate tetrahydrate at room temperature were mixed and stirred at $60{ }^{\circ} \mathrm{C}$ for $3 \mathrm{~h}$, followed by stirring at room temperature for $2 \mathrm{~h}$. The obtained solution was aged for $5 \mathrm{~h}$ at room temperature leading to the formation of a blood red precipitate (ATTM). The precipitate was washed with ethanol and dried in a vacuum oven at $60{ }^{\circ} \mathrm{C}$ for $24 \mathrm{~h}$. 


\subsubsection{Preparation of intercalated hydrophobic nano-MoS $S_{2}$ catalyst}

Firstly, ATTM (0.0125 mol) was added slowly into cyclohexylamine $(0.075 \mathrm{~mol})$ under vigorous stirring at ambient temperature to obtain the red organic intermediate. Then thiourea $(0.025 \mathrm{~mol})$ was dissolved completely in the red organic intermediate mixture under vigorous stirring at ambient temperature. The resulting dark red solution was transferred into a $50 \mathrm{~mL}$ stainless steel Teflon-lined autoclave, which was placed in an oven (160-240 ${ }^{\circ} \mathrm{C}$ and 5-20 h). The resulting black substance was centrifuged and thoroughly washed with ethanol absolute. Finally, the black substance was dried in a vacuum oven at $60{ }^{\circ} \mathrm{C}$ for $10 \mathrm{~h}$. The conditions of the synthesis including temperature, time, as well as the ratio of synthetic materials are summarized in Table 1.

The samples obtained by solvothermal synthesis $\left(\mathrm{MoS}_{2}\right.$-Solvothermal series) were abbreviated as Solvo-X-Y (X: I, II, III, IV, V, or VI; Y: 1, 2.). The $\mathrm{MoS}_{2}$-Solvothermal series samples were calcined in a tube furnace under protective Ar atmosphere at $800{ }^{\circ} \mathrm{C}$ for $4 \mathrm{~h}$ with a heating rate of $2{ }^{\circ} \mathrm{C} \cdot \mathrm{min}^{-1}$.

\subsubsection{Preparation of $\mathrm{MoS}_{2}$ catalyst using traditional hydrothermal method}

First, thiourea and ammonium molybdate tetrahydrate were dissolved in $35 \mathrm{~mL}$ deionized water at a molar ratio of $\mathrm{S}: \mathrm{Mo}=2: 1$ and transferred into a $50 \mathrm{~mL}$ stainless steel Teflon-lined autoclave, which was heated at $200-240{ }^{\circ} \mathrm{C}$. The resulting black substance was centrifuged and washed with ethanol absolute. Finally, the sample was dried in a vacuum oven at $60{ }^{\circ} \mathrm{C}$ for $10 \mathrm{~h}$. Products were named as $\mathrm{MoS}_{2}$-Hydrothermal series see Table 1 . The pure Hydro-2 sample with the highest crystallinity and defined morphology was selected for the subsequent analysis.

\subsection{Hydrodesulfurization test reaction}

\subsubsection{Evaluation of catalysts}

The performance of the $\mathrm{MoS}_{2}$-Solvothermal series and $\mathrm{MoS}_{2}$-Hydrothermal series 
catalysts was evaluated in a high-pressure fixed-bed reactor between $240^{\circ} \mathrm{C}$ and $320^{\circ} \mathrm{C}$ (a test was recorded at every $20^{\circ} \mathrm{C}$ ). These catalysts were pressed and sieved to retain 0.45 to $0.9 \mathrm{~mm}$ aggregates and mixed with quartz sand of similar size in order to ensure isothermal reactors. A feed solution of $1 \mathrm{wt}$ \% DBT in heptane and $1 \mathrm{wt}$. \% 4, 6-DMDBT in toluene were used. The liquid hourly space velocity (LHSV) was 3.0, 4.0, or $5.0 \mathrm{~h}^{-1}$, and the catalyst volume was $2,1.5$, and $1.2 \mathrm{~mL}$, respectively. The reaction pressure was $2.0 \mathrm{MPa}$, the feeding rate was $6 \mathrm{~mL} \cdot \mathrm{h}^{-1}$, and the $\mathrm{H}_{2} /$ feed ratio was 300 $(\mathrm{v} / \mathrm{v})$. The catalyst does not need pre-vulcanization process, and it is pre-activated directly at $240{ }^{\circ} \mathrm{C}$ for 6 hours. And then the temperature program with a ramp of $2{ }^{\circ} \mathrm{C} \cdot \mathrm{min}^{-1}$ was carried out (temperature ramp used for all samples). Liquid samples were collected every $4 \mathrm{~h}$ at each test point and analyzed using an Agilent $7820 \mathrm{GC}$.

Hence, the turnover frequency (TOF) is defined as the number of catalytic cycles per catalyst site and per unit of time (in this case in seconds) [28]. For the $\mathrm{MoS}_{2}$ catalyst, the TOF was calculated by the following formula:

$$
\mathrm{TOF}=\frac{F \cdot x}{\mathrm{n} \cdot \mathrm{D} \cdot 3600}
$$

where $\mathrm{F}$ is the reactant molar flow $\left(\mathrm{mol} \cdot \mathrm{h}^{-1}\right), \mathrm{x}$ is the reactant conversion $(\%), \mathrm{n}$ is the amount of $\mathrm{MoS}_{2}$ catalyst (mol), D is the $\mathrm{MoS}_{2}$ active sites dispersion.

The main products of the DBT HDS reaction are biphenyl (BP), cyclohexylbenzene $(\mathrm{CHB})$ and bicyclohexyl $(\mathrm{BCH})$. $\mathrm{BP}$ is mainly formed by the direct desulphurization-DDS pathway, while $\mathrm{CHB}$ and $\mathrm{BCH}$ are obtained through the hydrogenation-HYD pathway. Therefore, the HYD pathway selectivity of the reaction was calculated by the following equation:

$$
S_{H Y D / D D S}=\frac{\mathrm{C}_{\mathrm{CHB}}+\mathrm{C}_{\mathrm{BCH}}}{\mathrm{C}_{\mathrm{BP}}}
$$


where $\mathrm{C}_{\mathrm{BP}}, \mathrm{C}_{\mathrm{CHB}}$, and $\mathrm{C}_{\mathrm{BCH}}$ refer to the concentrations of $\mathrm{BP}, \mathrm{CHB}$, and $\mathrm{BCH}$ in the reaction, respectively (4,6-DMDBT HDS product distribution and HYD selectivity are presented in the supporting information, Figure S18).

The HDS of DBT is assumed as the pseudo-first-order reaction, and the rate constant $\kappa_{\mathrm{HDS}}\left(\mathrm{mol} \cdot \mathrm{g}^{-1} \cdot \mathrm{h}^{-1}\right)$ was calculated by the following equation:

$$
\kappa_{\mathrm{HDS}}=\frac{F}{m} \ln \left(\frac{1}{1-x}\right)
$$

where $F$ refers to the feeding rate of DBT $\left(\mathrm{mol} \cdot \mathrm{h}^{-1}\right), \mathrm{m}$ refers to the weight of $\mathrm{MoS}_{2}(\mathrm{~g})$, and the $\mathrm{x}$ refers to the HDS conversion (\%)

\subsubsection{Stability and cycle performance evaluation of catalysts}

The stability of the $\mathrm{MoS}_{2}$-Solvothermal series catalysts was evaluated through the continuous HDS reaction at $300{ }^{\circ} \mathrm{C}$ for $65 \mathrm{~h}$. Then, sample Solvo-IV-2 was selected for further cycle performance tests (five evaluation points were set up for each cycle between 220 and $300{ }^{\circ} \mathrm{C}$ ). The LHSV was $3.0 \mathrm{~h}^{-1}$ and the catalyst volume was $2 \mathrm{~mL}$. The operating conditions used were the same as for the HDS evaluation test.

\subsection{Characterization}

The size and morphology of the catalysts were characterized using a transmission electron microscope (TEM) at an operating voltage of $200 \mathrm{kV}$ (JEOL JSM-3010) and a scanning electron microscope (SEM-JEOL-7900). The average slab length $(\bar{L})$ and the average number of stacked layers $(\bar{N})$ were statistically calculated from the TEM pictures according to the following formulas:

$$
\bar{L}=\frac{\sum_{i=1}^{n} n_{i} L_{i}}{\sum_{i=1}^{n} n_{i}}
$$

where $L_{i}$ is the length of layer $\mathrm{i}$ and $n_{i}$ represents the number of layers with the 
length of the $L_{i}$, and

$$
\bar{N}=\frac{\sum_{i=1}^{m} m_{i} N_{i}}{\sum_{i=1}^{m} m_{i}}
$$

where $N_{i}$ is the stacking number of the layers and $m_{i}$ is the number of stacked units with a stacking number of $N_{i}$;

The $\mathrm{MoS}_{2}$ active sites dispersion (D) was calculated by the total number of Mo atoms $\left(M o_{T}\right)$, the total number of Mo atoms at the edges $\left(M o_{e}\right)$ and corners $\left(M o_{c}\right)$ :

$$
\mathrm{D}=\frac{M o_{e}+M o_{c}}{M o_{T}}=\frac{\sum_{i=1 \ldots t} 6 k_{i}-6}{\sum_{i=1 \ldots t} 3 k_{i}^{2}-3 k_{i}+1}
$$

where $\mathrm{k}_{\mathrm{i}}$ represents the number of Mo atoms at corresponding sites (edges and corners), $\mathrm{k}_{\mathrm{i}}$ is calculated from its length $\left(\mathrm{L}=0.32\left(2 \mathrm{k}_{\mathrm{i}}-1\right)\right)$, and $\mathrm{t}$ is the total number of slabs [29-32].

The Brunauer-Emmett-Teller (BET) specific surface area of samples was determined by $\mathrm{N}_{2}$ physisorption measurements at $77 \mathrm{~K}$ using a Quantachrome, Autosorb IQ; samples were activated at $180{ }^{\circ} \mathrm{C}$ for $10 \mathrm{~h}$ with a heating rate of $10^{\circ} \mathrm{C}$. $\min ^{-1}$

Powder X-ray diffraction (XRD) patterns were collected on a Panalytical X'Pert Pro MPD diffractometer with $\mathrm{Cu} \mathrm{K} \alpha$ radiation $(\lambda=0.15406 \mathrm{~nm})$. X-ray photoelectron spectral (XPS) analysis was carried out using a PH 5000 Versaprobe system with a monochromatic $\mathrm{Al} \mathrm{K} \alpha$ radiation $(\mathrm{h} v=1486.6 \mathrm{eV})$ to determine the valence state of elements in the catalyst. All binding energies were calibrated related to the $\mathrm{C}$ 1s peak $(284.6 \mathrm{eV})$. Energy dispersive spectroscopy (EDS) of the catalysts was performed on an EDAX XM2-30T apparatus.

The organic components were measured by ELCUBE CHNS/O elements analyzer of Elementar Company and X-ray fluorescence spectrometery (XRF). 
Thermogravimetric mass spectrometry (TG-MS) measurements, ultraviolet (UV), infrared (IR), and Raman spectroscopy measurements were carried out to determine the content of the organics in the catalysts. TG-MS was performed using a Netzsch TG-MS (STA449 F5) instrument in a nitrogen atmosphere in the range of $50-900{ }^{\circ} \mathrm{C}$ with a ramp of $2{ }^{\circ} \mathrm{C} \cdot \mathrm{min}^{-1}$. UV spectra were measured with a UV2700 Shimadzu instrument. Infrared spectra (IR) were measured with a VERTEX 70 instrument (Bruker) using the $\mathrm{KBr}$ technique. Raman measurements with an excitation laser of $632 \mathrm{~nm}$ were performed using a WITEC alpha300 R Confocal Raman instrument. The 5140- $\AA$ line from an argon ion laser was used to excite the samples with a power of $20 \mathrm{~mW}$.

Agilent's 7820 Gas Chromatography was used for characterization of the products of the HDS of DBT and 4, 6-DMDBT.

\section{Results and Discussion}

\subsection{Formation of intercalated hydrophobic nano- $\mathrm{MoS}_{2}$ catalyst}

The synthesis procedure for hydrophobic intercalated nano- $\mathrm{MoS}_{2}$ catalyst using an amine, is shown in Scheme 1. The synthesis procedure involves three steps: (1) amine substitution reaction between the ATTM and the solvent (cyclohexylamine) forming the organic intermediate (thiomolybdate) at room temperature; herein, the alkylammonium $\mathrm{RNH}_{3}{ }^{+}$cations replace the ammonium cations $\mathrm{NH}_{4}{ }^{+}$of the ATTM proven by the formation of ammonia (Figure S1,supporting information). No peaks characteristic of ATTM were found in the XRD patterns of the intermediate and the $\mathrm{MoS}_{2}$-solvothermal sample (Solvo-IV-2) (Figure S2) thus confirming that the ATTM was decomposed completely; (2) dehydrogenation of cyclohexylamine leading to the formation of $\mathrm{C}_{6} \mathrm{H}_{10}=\mathrm{NH}$ and $\mathrm{H}_{2}$ under increasing the temperature and pressure (1)in 
Scheme 1), followed by the catalytic reduction of the organic intermediate in hydrogen atmosphere resulting in the generation of $\mathrm{MoS}_{2}, \mathrm{H}_{2} \mathrm{~S}, \mathrm{C}_{6} \mathrm{H}_{10}=\mathrm{NH}$, and $\mathrm{NH}_{3}$ under the catalysis of thiourea (2)in Scheme 1). Thiourea promotes electron transfer between the reducing agent $\left(\mathrm{H}_{2}\right)$ and the organic intermediate (note: no product was obtained without thiourea at $170{ }^{\circ} \mathrm{C}$ and $180{ }^{\circ} \mathrm{C}$ as shown in Table 1. VII-2/3); the catalytic action of thiourea was confirmed and the relevant information is presented in part III-1, supporting information; (3) intercalated Nano-MoS 2 with organic compound $\mathrm{C}_{6} \mathrm{H}_{10}=\mathrm{NH}$ as interpenetrating layer was obtained due to the $\mathrm{p}-\pi$ conjugate effect $\left(\mathrm{C}_{6} \mathrm{H}_{10}=\mathrm{NH}\right.$ contains $\pi$ bonds, and $\mathrm{S}$ in $\mathrm{MoS}_{2}$ contains $\mathrm{p}$ orbitals). The presence of the organic matter $\left(\mathrm{C}_{6} \mathrm{H}_{10}=\mathrm{NH}\right)$ may broaden and stabilize the interlayer spacing structure of the $\mathrm{MoS}_{2}$ by conjugate effect. (The reaction equation is presented in part III-2)

When the organic solvent is changed to aniline or the reaction temperature is lower than $170^{\circ} \mathrm{C}$, the targeted samples were not obtained (Table $1 . \mathrm{V}-1 / 2$ and VI-1/2). At any temperatures used for the syntheses, the desired pure phase was obtained after 5 hours (Table 1). The samples Solvo-II-2, Solvo-III-2, and Solvo-IV-2 are pure crystalline materials which were further subjected to characterization and catalytic tests.

Furthermore, sample Solvo-IV-2 was studied by IR and UV spectroscopy. The appearance of an absorption peak at $1638 \mathrm{~cm}^{-1}$ in the IR spectrum (Figure 1-1) and the absorption band at $313 \mathrm{~nm}$ in the UV spectrum (Figure 1-2) indicates the existence of $\mathrm{C}=\mathrm{N}$ group, and the absence of a primary amine $\left(-\mathrm{NH}_{2}\right)$, which further confirmed the occurrence of dehydrogenation of cyclohexylamine. In addition, no bands corresponding to S-S, N-C=S or C-S were detected in the IR (Figure 1-1) and Raman (Figure 8) spectra, indicating that sulfur is only present in the $\mathrm{MoS}_{2}$. The following 
atomic ratio $\mathrm{H}: \mathrm{C}: \mathrm{N}: \mathrm{S}: \mathrm{Mo}=8.0: 3.8: 0.5: 2.5: 1$ is determined for sample Solvo-IV-2 and the organic matter is $26.0 \%$ (Table S1). The Mo:S ratio is $1: 2.5$ that is close to the stoichiometry of $\mathrm{MoS}_{2}$.

The theoretical ratio for $\mathrm{MoS}_{2}$ and $\mathrm{C}_{6} \mathrm{H}_{10}=\mathrm{NH}$ is 3:2. Due to the steric hindrance effect, two adjacent $\mathrm{S}$ atoms of $\mathrm{MoS}_{2}$ will not form conjugated structures with the organic $\left(\mathrm{C}_{6} \mathrm{H}_{10}=\mathrm{NH}\right)$ simultaneously. Thus the theoretical ratio $\mathrm{H}: \mathrm{C}: \mathrm{N}: \mathrm{S}: \mathrm{Mo}=7.3$ : 4.0: 0.6: 2.0: 1.0 and the organic content $(28.7 \%)$ determined are consistent with the experimental results (26.0\% according to XRF and $22.6 \%$ according to TG-MS, Figure 2; Table S1 and Table S2).

\subsection{Characterization of intercalated and multilayer $\mathrm{MoS}_{2}$ samples}

The phase and crystal structure of sample Solvo-IV-2 was investigated by XRD (Figure 3). Both the as-synthesized Solvo-IV-2 and sample Hydro-2 have the characteristic Bragg peaks of crystalline $\mathrm{MoS}_{2}$; the major peaks corresponding to $2 \mathrm{H}-\mathrm{MoS}_{2}\left(14.4^{\circ}(002), 33.2^{\circ}(100)\right.$, and $58.5^{\circ}$ (110) of the PDF \# 37-1492 card) are present. Compared with the sample Hydro-2 (Figure 3b), the sample Solvo-IV-2 had lower intensity peaks, which can be due to the low crystallinity and small size. Furthermore, the (002) peak representative of the number of stacked layers $[33,34]$ is weak, indicating that as-synthesized Solvo-IV-2 sample is a monolayer $\mathrm{MoS}_{2}$, and the organic group has inserted the layer gap successfully and broadened interlayer spacing. The XRD patterns of samples synthesized for different synthesis time and temperature are showed in Figure S3. The intensity of the (100) and (110) peaks of sample Solvo-IV-2 subjected to calcination at $800{ }^{\circ} \mathrm{C}$ in $\mathrm{Ar}$ atmosphere changed due to continuous growth resulting in higher crystallinity (Figure S4.). The intensity of the (002) peak is still low revealing that sample Solvo-IV-2 still exists as a monolayer after calcination; the as-synthesized intercalated monolayer $\mathrm{MoS}_{2}$ shows high thermal 
stability.

The hydrophobicity of sample Solvo-IV-2 was measured by air-water contact angle tests. As shown in Figure 4, the contact angle for sample Solvo-IV-2 is $105^{\circ}$ (1a) and this sample is organic solvent-friendly (Figure 4-2), whereas for the conventional sample Hydro-2 the contact angle is $26^{\circ}(1 \mathrm{~b})$. This shows that sample Solvo-IV-2 is highly hydrophobic. In addition, the contact angle for sample Solvo-IV-2 with different organic reagents (Heptane, Methylcyclohexane, Methylbenzene, and Thiophene) confirmed the extremely high hydrophobicity (Figure S5). The high hydrophobicity is related to the presence of organic groups promoting the contact between the organic reactants and the active sites.

The morphology of the as-synthesized hydrophobic sample Solvo-IV-2 is shown in Figure 5a. The sample is composed of nanoballs with a size of 70-100 nm, which differs significantly from the Hydro-2 with micron-size flower morphology (Figure 5b). Moreover, the particles gradually became larger with increasing the synthesis temperature (Figure S6). After calcination of sample Solvo-IV-2 in Ar at $800{ }^{\circ} \mathrm{C}$, due to the pyrolysis and polycondensation of organic components, pores and flakes appeared on their surfaces (Figure S7).

The porosity of the sample Solvo-IV-2 after calcination was analyzed by nitrogen adsorption. The specific surface area decreased (Table S3) while mesopores are formed (Figure S8).

In order to further investigate the inner-structure of the solvothermal-series samples, TEM study was carried out. The interlayer spacing of multi-layer $\mathrm{MoS}_{2}$ samples ranges from 0.62 to $0.65 \mathrm{~nm}$ [35]. The as-synthesized sample Solvo-IV-2 exhibits monolayer structure $(0.74 \mathrm{~nm})$ with a curved lamella shape (Figure 6a). Because of the $\mathrm{p}-\pi$ conjugate effect, the organics intercalated into the $\mathrm{MoS}_{2}$ layers and 
widen the layer spacing. The curved structure is caused by the formation of coordinated structure between the organics and the $\mathrm{MoS}_{2}$ [36-39]. With increasing the synthesis temperature $\left(170-200{ }^{\circ} \mathrm{C}\right)$, the layers length for samples (Solvo-IV-2, Solvo-III-2, and Solvo-II-2) maintained around 6-7 $\mathrm{nm}$ and the average stacking number ranged from 1 to 1.4 respectively (Figure $6 \mathrm{c}, \mathrm{d}$ ). After calcination at $800^{\circ} \mathrm{C}$, the length of the layers increased to 10-18 $\mathrm{nm}$ and they become more ordered, but still appear as monolayer. The narrowest layer spacing is $0.77 \mathrm{~nm}$ (Figure S9) which is larger than that of the multi-layer sample Hydro-2 (0.62 nm). This result is in agreement with the XRD results (Figure S4). The organic groups lead to the formation of intercalated $\mathrm{MoS}_{2}$ (Solvo-IV-2) with excellent thermal stability.

The chemical composition of sample Solvo-IV-2 was determined by XPS. The spectra containing the Mo $3 d$ and $S 2 p$ peaks are shown in Figure $S 10$ a. The $S 2 p$ spectrum (Figure S10, a-1) can be divided into S 2 $p_{3 / 2}(161.4 \mathrm{eV})$ and $\mathrm{S} 2 \mathrm{p}_{1 / 2}(162.2 \mathrm{eV})$, which correspond to $\mathrm{S} 2 \mathrm{p}$ of $\mathrm{MoS}_{2}, \mathrm{~S}$ peaks $(168.5 \mathrm{eV}$ and $169.5 \mathrm{eV})$ representing the $\mathrm{SO}_{4}{ }^{2-}$, and the other set of $\mathrm{S}$ peaks $(163.4 \mathrm{eV}$ and $164.7 \mathrm{eV})$ suggesting the presence of amorphous sulfur [40]. Moreover, compared with the sample prepared by traditional hydrothermal method (Figure 7b (Mo 3d $3 / 2: 232.5 \mathrm{eV}$ and Mo 3d $\mathrm{d}_{5 / 2} 229.4 \mathrm{eV}$ )), the sample Solvo-IV-2 has lower bonding energy (BE) (Figure 7a, Mo 3d $\mathrm{d}_{3 / 2}(231.4 \mathrm{eV}$ ) and

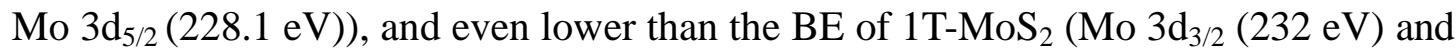
Mo $3 \mathrm{~d}_{5 / 2}(228.9 \mathrm{eV})$ [41-43]), which is indicating that the electron density of Mo increased. This is due to the chemical interactions between the organic groups and nano- $\mathrm{MoS}_{2}$ instead of van der Waals interactions. After calcination, the binding energy of samples Solvo-IV-2 shifted to the higher value, which is related to the weaker binding force between Mo and organic groups, caused by the carbonation of the latest (Figure S11). 
The EDX results for sample Solvo-IV-2 are shown in Figure 8.a; the atomic ratio of $\mathrm{S}$ to Mo is about 2.7, which is close to the stoichiometry of $\mathrm{MoS}_{2}$ and significantly different for sample Hydro-2 (Figure 8.b). The elemental distribution in sample Solvo-IV-2 is uniform as shown in the EDX spectrum (Figure S12.2-5). After calcination of sample Solvo-IV-2 (Figure S13.2-5), the homogeneous elemental composition is revealed by EDX, while the content of $\mathrm{C}$ is reduced as shown in Table S4.

The spectrum of sample Hydro- 2 contains a peak $\mathrm{E}_{2 \mathrm{~g}}{ }^{1}\left(383 \mathrm{~cm}^{-1}\right)$, a peak $\mathrm{A}_{1 \mathrm{~g}}(408$ $\mathrm{cm}^{-1}$ ) and the LA(M) symmetry peaks, indicating the multilayer structure (Figure 9) $[44,45]$. While the sample Solvo-IV-2 does not contain these peaks, suggesting that the organics were inserted in the interlayer spacing and promoted the formation of single layer structure. Furthermore, the appearance of the $\mathrm{MoO}_{3}$ peaks $\left(800-900 \mathrm{~cm}^{-1}\right.$, marked in Figure 9) and the $\mathrm{MoO}_{2}$ peaks ( 365 and $748 \mathrm{~cm}^{-1}$, marked in Figure 9) indicate that the Solvo-IV-2 sample is easily oxidized during the measurements, while the $\mathrm{MoS}_{2}$ hydrothermal series sample (Hydro-2) do not show these peaks under the same condition (Figure S14). The intercalated $\mathrm{MoS}_{2}$ (monolayer) sample is better accessible and has higher activity than the multilayer $\mathrm{MoS}_{2}$ (Hydro-2).

\subsection{Catalytic evaluation of intercalated $\mathrm{MoS}_{2}$ and multilayer samples}

The HDS catalytic activity, selectivity, and stability of the two samples in conversion of DBT were evaluated. Under the same reaction conditions, the catalytic performance of the $\mathrm{MoS}_{2}$-Solvothermal series (samples Solvo-II-2, Solvo-III-2, and Solvo-IV-2) was significantly better than that of the $\mathrm{MoS}_{2}$-Hydrothermal series (sample Hydro-2) (Figure 10a). The DBT conversion was only $24.3 \%$ for the Hydro-2 catalyst, while over $60 \%$ for the $\mathrm{MoS}_{2}$-Solvothermal series` catalysts were measured at $280{ }^{\circ} \mathrm{C}$. TOF values calculated for all catalysts are summarized in Table 2.1 (details are 
provided in SI Part III-3). At DBT conversion of $13 \%$, the TOF for the Solvo-IV-2 catalyst is $0.26 \cdot 10^{-2} \mathrm{~s}^{-1}$, but for the Hydro-2 catalyst is $0.14 \cdot 10^{-3} \mathrm{~s}^{-1}$ (Table 2.1). This is consistent with the excellent catalytic performance of the $\mathrm{MoS}_{2}$-Solvothermal series catalyst. This is in agreement with the kinetics results shown in Table 2.2, the catalytic activity ( $\mathrm{k}_{\mathrm{HDS}}$ ) of the $\mathrm{MoS}_{2}$-Solvothermal series catalyst is higher than that of traditional hydrothermally prepared catalysts under the same reaction temperature.

The differences in the activities of solvothermal series samples are shown in Figure 10a. The TEM images show that sample Solvo-IV-2 synthesized at $170{ }^{\circ} \mathrm{C}$ contains single layer in highly dispersed state, sample Solvo-III- 2 synthesized at $180{ }^{\circ} \mathrm{C}$ consists of single component, and sample Solvo-II-2 synthesized at $200{ }^{\circ} \mathrm{C}$ feature cross stacking multi-ordered structure (Figure 12). In the HDS reaction, sample Solvo-IV-2 is favorable for the contact between the reactants and the active sites, while the cross stacking multi-ordered structure decrease the utilization of active sites. These results are consistent with the TOF and catalytic activity of the samples ( $\mathrm{k}_{\mathrm{HDS}}$ ).

The effect of liquid hourly space velocity on the conversion rate was investigated in the temperature range of $240-320{ }^{\circ} \mathrm{C}$, and no obvious relation was found (Figure S15.a). In addition, after $68 \mathrm{~h}$ of continuous reaction, the $\mathrm{MoS}_{2}$-Solvothermal series samples still maintained high stability (Figure S15.b). After five reaction cycles, the sample Solvo-IV-2 has good performance thus demonstrating the long life of the catalyst (Figure 13).

The possible reasons for the high performance of Solvo-IV-2 catalyst are as follows:

(i) The monolayer structure, which is due to organic group intercalation, contains more highly dispersed rim sites than conventional multilayer $\mathrm{MoS}_{2}$. (ii) The intercalated $\mathrm{MoS}_{2}$-Solvothermal series possess strong hydrophobic characteristic, and 
the diffusion of organic reactants is beneficial; (iii) The larger layer spacing broadened by the organic group is more favorable for the adsorption and desorption of reactant molecules (DBT) at the rim sites, thus the utilization of the rim sites is improved; (iv) the low crystallinity of $\mathrm{MoS}_{2}$-Solvothermal series benefits the higher catalytic activity because of the larger effective rim sites [46,47]; (v) The long-lasting catalytic activity $\left(300{ }^{\circ} \mathrm{C}\right)$ benefits from the high thermal stability of the intercalated $\mathrm{MoS}_{2}$-Solvothermal series samples.

The distribution of hydrodesulfurization products during the catalytic test is shown in Figure S16. It was found that the hydrogenation selectivity of the intercalated $\mathrm{MoS}_{2}$-Solvothermal series samples was as high as 3.6 (Figure 10b). This indicates that the disperse active sites of intercalated hydrophobic $\mathrm{MoS}_{2}$ favor the hydrogenation pathway (HYD). Since the synthesized intercalated monolayer $\mathrm{MoS}_{2}$ has rim sites only, and this proves that rim sites favor the HYD pathway in the HDS reaction. The benefits of rim for the HYD path was reported [18]. After the calcination of the $\mathrm{MoS}_{2}$-solvothermal series samples at $800^{\circ} \mathrm{C}$, the decrease of $\mathrm{HYD}$ selectivity was more significant than the DDS selectivity (Figure S17). This is due to the longer lamellar length of calcined solvothermal series samples (Figure 6c) resulting into lower rim/edge site ratio, which leads to a decrease of HYD pathway selectivity. The increase of the crystallinity of the sample (Figure S4) also has a certain inhibitory effect on the catalytic performance [46, 47].

The HDS catalytic activity and selectivity of samples Solvo-IV-2 and Hydro-2 in the conversion of 4, 6-DMDBT were also evaluated (Figure 11.a). The HYD pathway selectivity of sample Solvo-IV-2 (Figure 11.b) is much higher than that of the traditional hydrothermal sample Hydro-2; the distribution of products is shown in Figure S18. 


\subsection{Mass and heat transfer limitations}

DBT hydrodesulfurization over the $\mathrm{MoS}_{2}$-Solvothermal series catalyst (sample Solvo-IV-2) with different size was carried out at $260{ }^{\circ} \mathrm{C}$ to verify the effect of mass transfer limitation. The TOF did not change significantly until the particle size was $1.4 \mathrm{~mm}$, indicating no mass transfer limitation with the as-synthesized catalyst (0.45-0.9 mm) (Figure S19). Mass and heat transfer calculations using the Mears and Mears-Prater criterion are provided in the SI (section III -5). These results also confirmed the absence of mass or heat transfer limitation during the reaction.

\section{Conclusion}

In summary, intercalated hydrophobic nano- $\mathrm{MoS}_{2}$ hydrodesulfurization catalysts (monolayer) have been synthesized. The $\mathrm{MoS}_{2}$ hydrodesulfurization catalysts have a size of $60-100 \mathrm{~nm}$ and a length of the individual layers of 3-16 nm. The organic groups successfully inserts $\mathrm{MoS}_{2}$ layers, widen layer spacing of $\mathrm{MoS}_{2}$, and promote the formation of highly hydrophobic and stables intercalated monolayered structure. The as-synthesized intercalated hydrophobic monolayer nano-MoS 2 catalysts have better HDS performance and higher HYD/DDS selectivity than the traditional $\mathrm{MoS}_{2}$ catalysts. The intercalated hydrophobic monolayer nano- $\mathrm{MoS}_{2}$ catalyst not only provides a new model for further study of the specific selectivity in the HDS, but also possesses a wide application prospect in the ultra-deep desulfurization.

\section{Acknowledgment}

The authors gratefully acknowledged funding from Thousand Talents Program for Foreign Experts (WQ20152100284). The French-China Science Foundation (FFCSA), the National Natural Science Foundation of China (Grant No. 21975285, No. U1862118, No.21991091). The Fundamental Research Funds for the Central Universities (No. 18CX05018A, 20CX02203A), the State Key Laboratory of 
Advanced Technology for Materials Synthesis and Processing (Wuhan University of Technology) (No. 2018-KF-13). 


\section{References}

[1] I.V. Babich, J.A. Moulijn, Science and technology of novel processes for deep desulfurization of oil refinery streams: a review $\bar{k}$, Fuel, 82 (2003) 607-631.

[2] K.G. Knudsen, B.H. Cooper, H. Topsøe, Catalyst and process technologies for ultra low sulfur diesel, Applied Catalysis A General, 189 (1999) 205-215.

[3] B. Pawelec, R. Navarro, J. Camposmartin, J.G. Fierro, Towards near zero-sulfur liquid fuels: a perspective review, Catalysis Science \& Technology1(2011) 23-42.

[4] C.S. Song, An overview of new approaches to deep desulfurization for ultra-clean gasoline, diesel fuel and jet fuel $\hat{\sim}$, Catalysis Today, 86 (2003) 211-263.

[5] A. Stanislaus, A. Marafi, M.S. Rana, Recent advances in the science and technology of ultra low sulfur diesel (ULSD) production, Catalysis Today, 153 (2010) 1-68.

[6] A.N. Varakin, A.V. Mozhaev, A.A. Pimerzin, P.A. Nikulshin, Comparable investigation of unsupported $\mathrm{MoS}_{2}$ hydrodesulfurization catalysts prepared by different techniques: Advantages of support leaching method, Applied Catalysis B: Environmental, 238 (2018) 498-508.

[7] T. Weber, J.A.R. Van Veen, A density functional theory study of the hydrodesulfurization reaction of dibenzothiophene to biphenyl on a single-layer NiMoS cluster, Catalysis Today, 130 (2008) 170-177.

[8] D.H. Broderick, B.C. Gates, Hydrogenolysis and hydrogenation of dibenzothiophene catalyzed by sulfided $\mathrm{CoO}-\mathrm{MoO} 3 / \gamma-\mathrm{Al} 2 \mathrm{O} 3$ : The reaction kinetics, Aiche Journal, 27 (1981) 663-673.

[9] A.S. Walton, J.V. Lauritsen, H. Topsøe, F. Besenbacher, $\mathrm{MoS}_{2}$ nanoparticle morphologies in hydrodesulfurization catalysis studied by scanning tunneling microscopy, Journal of Catalysis, 308 (2013) 306-318.

[10] P.A. Nikulshin, D.I. Ishutenko, A.A. Mozhaev, K.I. Maslakov, A.A.J.J.o.C. Pimerzin, Effects of composition and morphology of active phase of $\mathrm{CoMo} / \mathrm{Al}_{2} \mathrm{O}_{3}$ catalysts prepared using $\mathrm{Co}_{2} \mathrm{Mo}_{10}$-Heteropolyacid and chelating agents on their catalytic properties in HDS and HYD reactions, Journal of catalysis, 312 (2014) 152-169.

[11] D. Ferdous, A.K. Dalai, J. Adjaye, L. Kotlyar, Surface morphology of $\mathrm{NiMo} / \mathrm{Al}_{2} \mathrm{O}_{3}$ catalysts incorporated with boron and phosphorus: Experimental and simulation, Applied Catalysis A: General, 294 (2005) 80-91. 
[12] J.L. Pinilla, H. Purón, D. Torres, I. Suelves, M. Millan, Ni-MoS 2 supported on carbon nanofibers as hydrogenation catalysts: Effect of support functionalisation, Carbon, 81 (2015) 574-586.

[13] G. Alonso, R.R. Chianelli, WS2 catalysts from tetraalkyl thiotungstate precursors and their concurrent in situ activation during HDS of DBT, Journal of Catalysis, 221 (2004) 657-661.

[14] R. Huirache-Acuña, M.A. Albiter, J. Espino, C. Ornelas, G. Alonso-Nuñez, F. Paraguay-Delgado, J.L. Rico, R. Martínez-Sánchez, Synthesis of Ni-Mo-W sulphide catalysts by ex situ decomposition of trimetallic precursors, Applied Catalysis A: General, 304 (2006) 124-130.

[15] P.A. Nikulshin, P.P. Minaev, A.V. Mozhaev, K.I. Maslakov, M.S. Kulikova, A.A. Pimerzin, Investigation of co-effect of 12-tungstophosphoric heteropolyacid, nickel citrate and carbon-coated alumina in preparation of NiW catalysts for HDS, HYD and HDN reactions, Applied Catalysis B: Environmental, 176-177 (2015) 374-384.

[16] M.Daage, R.Chianelli, Structure-function relations in molybdenum sulfide catalysts: the" rim-edge" model. Journal of Catalysis, 149 (2) (1994) 414-427.

[17] P. Zheng, A. Duan, K. Chi, L. Zhao, C. Zhang, C. Xu, Z. Zhao, W. Song, X. Wang, J. Fan, Influence of sulfur vacancy on thiophene hydrodesulfurization mechanism at different $\mathrm{MoS}_{2}$ edges: A DFT study. Chemical Engineering Science, 164(2017) 292-306.

[18] P.G. Moses, B. Hinnemann, H. Topsøe, J.K. Nørskov, The hydrogenation and direct desulfurization reaction pathway in thiophene hydrodesulfurization over $\mathrm{MoS}_{2}$ catalysts at realistic conditions: A density functional study, Journal of Catalysis, 248 (2007) 188-203.

[19] W. AS, L. JV, T. H, B. F, MoS 2 nanoparticle morphologies in hydrodesulfurization catalysis studied by scanning tunneling microscopy, Journal of Catalysis, 308 (2013) 306-318.

[20] J.V. Lauritsen, M. Nyberg, J.K. Nørskov, B.S. Clausen, H. Topsøe, E. Lgsgaard, F. Besenbacher, Hydrodesulfurization reaction pathways on $\mathrm{MoS}_{2}$ nanoclusters revealed by scanning tunneling microscopy, Journal of Catalysis 224 (2004) 94-106

[21] D. Duphil, Chemical synthesis of molybdenum disulfide nanoparticles in an 
organic solution, Journal of Materials Chemistry, 12 (2002) 2430-2432.

[22] E.A. Ponomarev, A. Albu-Yaron, R. Tenne, C. Levy-Clement, ChemInform Abstract: Electrochemical Deposition of Quantized Particle $\mathrm{MoS}_{2}$ Thin Films, Cheminform, 29 (2010) no-no.

[23] R. Sen, A. Govindaraj, K. Suenaga, S. Suzuki, H. Kataura, S. Iijima, Y. Achiba, Encapsulated and hollow closed-cage structures of $\mathrm{WS}_{2}$ and $\mathrm{MoS}_{2}$ prepared by laser ablation at $450-1050^{\circ} \mathrm{C}$, Chemical Physics Letters340 (2001) 242-248.

[24] S. Yoo, S.A. Akbar, K.H. Sandhage, Nanocarving of Bulk Titania Crystals into Oriented Arrays of Single - Crystal Nanofibers via Reaction with Hydrogen Bearing Gas, Advanced Materials, 16 (2004) 260-264.

[25] E. Kikuchi, T. Ino, Y. Morita, Catalytic synthesis of hydrocarbons from carbon monoxide and hydrogen on lamellar compound of graphite intercalated by ferric chloride, Journal of Catalysis 57 (1979) 27-34.

[26] A. Goñi, M. Insausti, L.M. Lezama, T. Rojo, J.L. Pizarro, M.I. Arriortua, Synthesis, Structure, and Magnetic Properties of the New Layered Compound $\mathrm{HNiPO}_{4} \cdot \mathrm{H}_{2} \mathrm{O}$. Study of Alkylamine Intercalated Compounds, Chemistry of Materials, 8 (1996) 1052-1060.

[27] A. Tsujimura, M. Uchida, A. Okuwaki, Synthesis and sulfate ion-exchange properties of a hydrotalcite-like compound intercalated by chloride ions, Journal of Hazardous Materials, 143 (2006) 582-58.

[28] M. Boudart, Turnover rates in heterogeneous catalysis, Chem. Rev. 95 (1995)661-666.

[29] Y. Tian, Z. Xu, L. Shen, F. Meng, L. Tang, Y. Deng, Z. Wang, Synthesis of amorphous $\mathrm{MoS}_{2}$ nanospheres by hydrothermal reaction, Materials Letters, 60 (2006) 527-529.

[30] D. Zuo, M. Vrinat, H. Nie, F. Maugé, Y. Shi, M. Lacroix, D. Li, The formation of the actIVe phases in sulfided $\mathrm{NiW} / \mathrm{Al}_{2} \mathrm{O}_{3}$ catalysts and their evolution during post-reduction treatment, Catalysis Today, 93 (2004) 751-760.

[31] S. Sharifvaghefi, Y. Bo, Z. Ying, New Insights on the role of sulfur vacancies on dibenzothiophene hydrodesulfurization over $\mathrm{MoS}_{2}$ edges, Applied Catalysis A General, (2018) S0926860X18302631-.

[32] E. José, B.M. C., G.A. W., C.-J.M. A., A.-C. Carlos, T.J. A., S.-C.D. A., Highly active P-doped sulfided NiMo/alumina HDS catalysts from Mo-blue by using 
saccharose as reducing agents precursor, Applied Catalysis B: Environmental, 237 708-720.

[33] W.U. Huadong, A. Duan, Z. Zhen, Q.I. Dinghong, L.I. Jianmei, L. Bing, G. Jiang, L. Jian, Y. Wei, Z. Xiao, Preparation of NiMo/KIT-6 hydrodesulfurization catalysts with tunable sulfidation and dispersion degrees of active phase by addition of citric acid as chelating agent, Fuel, 130 (2014) 203-210.

[34] N. Li, Y. Chai, Y. Li, Z. Tang, B. Dong, Y. Liu, C. Liu, Ionic liquid assisted hydrothermal synthesis of hollow vesicle-like $\mathrm{MoS}_{2}$ microspheres, Materials Letters, 66 (2012) 236-238.

[35] Q.H. Wang, K. Kalantar-Zadeh, A. Kis, J.N. Coleman, M.S. Strano, Electronics and optoelectronics of two-dimensional transition metal dichalcogenides, Nature Nanotechnology, 7 (2012) 699-712.

[36] C. Bara, A.F. Lamic-Humblot, E. Fonda, A.S. Gay, A.L.Taleb, E.Devers, M. Digne, G.D. Pirngruber, X. Carrier, Surface-dependent sulfidation and orientation of $\mathrm{MoS}_{2}$ slabs on alumina-supported model hydrodesulfurization catalysts. Journal of catalysis, 2016, 344, 591-605.

[37] Y. Li, A. Li, F. Li, D. Liu, Y. Chai, C. Liu, Application of HF etching in a HRTEM study of supported $\mathrm{MoS}_{2}$ catalysts, Journal of Catalysis, 317 (2014) 240-252.

[38] G. Li, C. Li, H. Tang, K. Cao, J. Chen, F. Wang, Y. Jin, Synthesis and characterization of hollow $\mathrm{MoS}_{2}$ microspheres grown from $\mathrm{MoO}_{3}$ precursors, Journal of Alloys \& Compounds, 501 (2010) 0-281.

[39] K.D. Kim, Y.K Lee, ActIVe phase of dispersed $\mathrm{MoS}_{2}$ catalysts for slurry phase hydrocracking of vacuum residue. Journal of catalysis, 369 (2019) 111-121.

[40] Y. Hu, D.H.C. Chua, Synthesizing 2D $\mathrm{MoS}_{2}$ Nanofins on carbon nanospheres as catalyst support for Proton Exchange Membrane Fuel Cells. Scientific Reports, 6 (2016) 28088.

[41] L. Cai, J. He, Q. Liu, T. Yao, L. Chen, W. Yan, F. Hu, Y. Jiang, Y. Zhao, T.J.J.o.t.A.C.S. Hu, Vacancy-Induced Ferromagnetism of $\mathrm{MoS}_{2}$ Nanosheets, 137 (2015) 2622

[42] Y. Qi, Q. Xu, Y. Wang, B. Yan, Z.J.A.N. Chen, $\mathrm{CO}_{2}$-Induced Phase Engineering: A Protocol for Enhanced Photoelectrocatalytic Performance of 2D $\mathrm{MoS}_{2}$ Nanosheets, 10 (2016) 2903-2909. 
[43]. L. Guardia, J.I. Paredes, J.M. Munuera, S. Villar-Rodil, J.M.D.J.A.A.M. Tascon, Interfaces, Chemically Exfoliated $\mathrm{MoS}_{2}$ Nanosheets as an Efficient Catalyst for Reduction Reactions in the Aqueous Phase, 6 (2014)21702-21710.

[44] H. Li, Q. Zhang, C.C.R. Yap, B.K. Tay, T.H.T. Edwin, A. OlIVier, D. Baillargeat, From Bulk to Monolayer $\mathrm{MoS}_{2}$ : Evolution of Raman Scattering, Advanced Functional Materials,22 (2012) 1385-1390.

[45] S. Najmaei, Z. Liu, P.M. Ajayan, J. Lou, Thermal effects on the characteristic Raman spectrum of molybdenum disulfide $\left(\mathrm{MoS}_{2}\right)$ of varying thicknesses, Applied Physics Letters, 100 (2012) 1271.

[46] D. Mahajan, C.L. Marshall, N. Castagnola, J. Hanson, Sono synthesis and characterization of nano-phase molybdenum-based materials for catalytic hydrodesulfurization, Applied Catalysis A: General ,258 (2004) 83-91.

[47] Y. Mastai, M. Homyonfer, A. Gedanken, G.Hodes, ChemInform Abstract: Room Temperature Sonoelectrochemical Synthesis of Molybdenum Sulfide Fullerene - Like Nanoparticles, Cheminform ,30 (1999). 


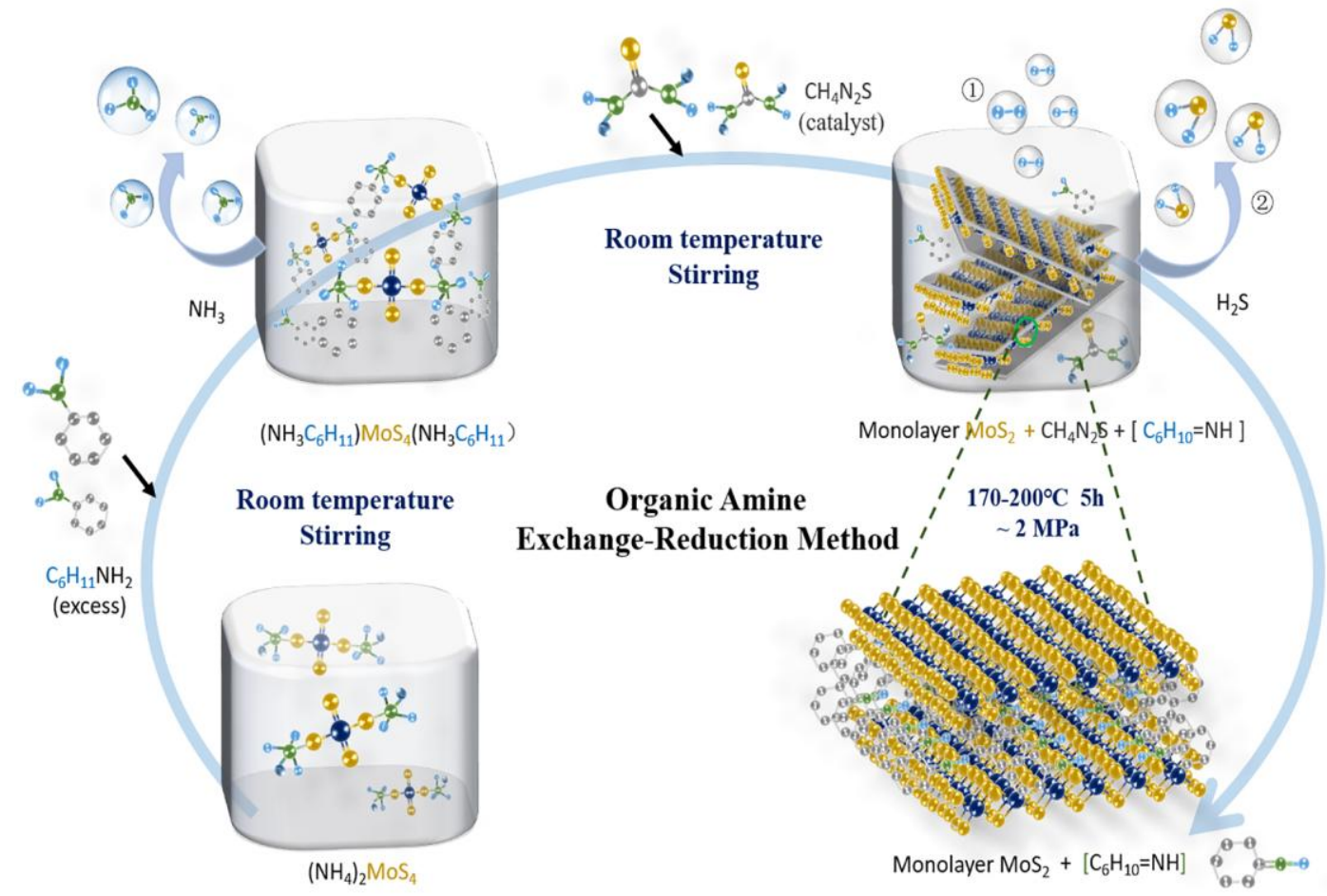

Scheme.1 Schematic presentation of the synthesis of nano-MoS 2 hydrophobic monolayer catalyst. 


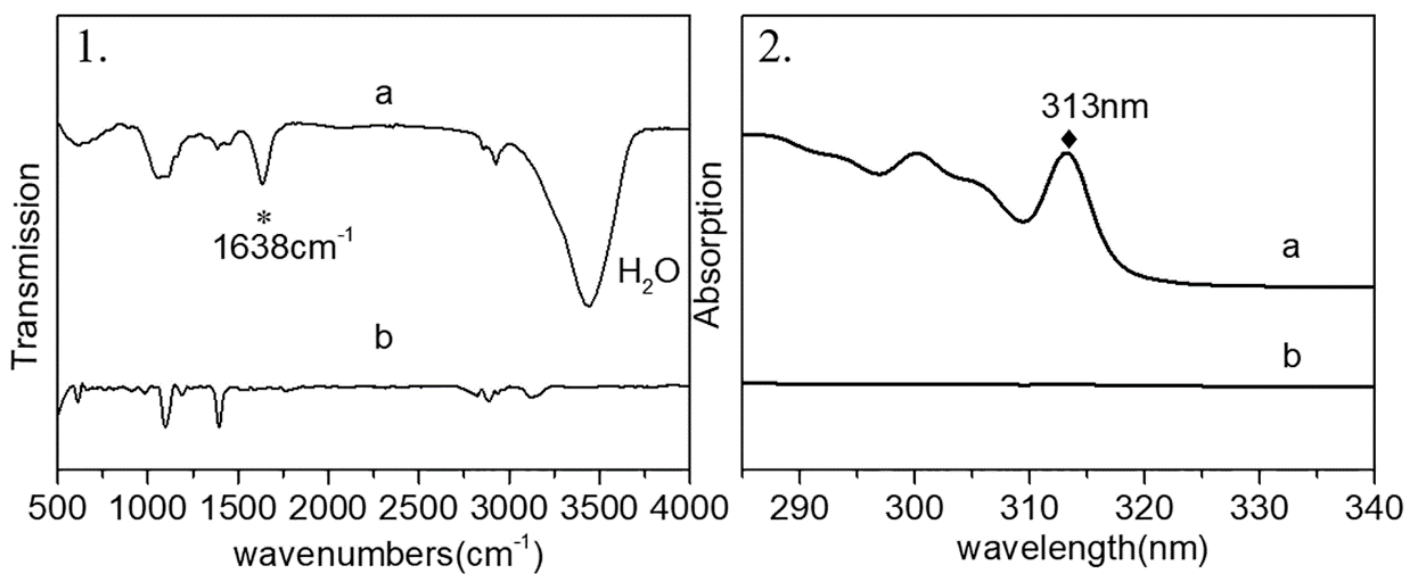

Figure 1. IR (1) and UV (2) spectra of $\mathrm{MoS}_{2}$ samples (a) Solvo-IV-2, and (b) Hydro-2. 


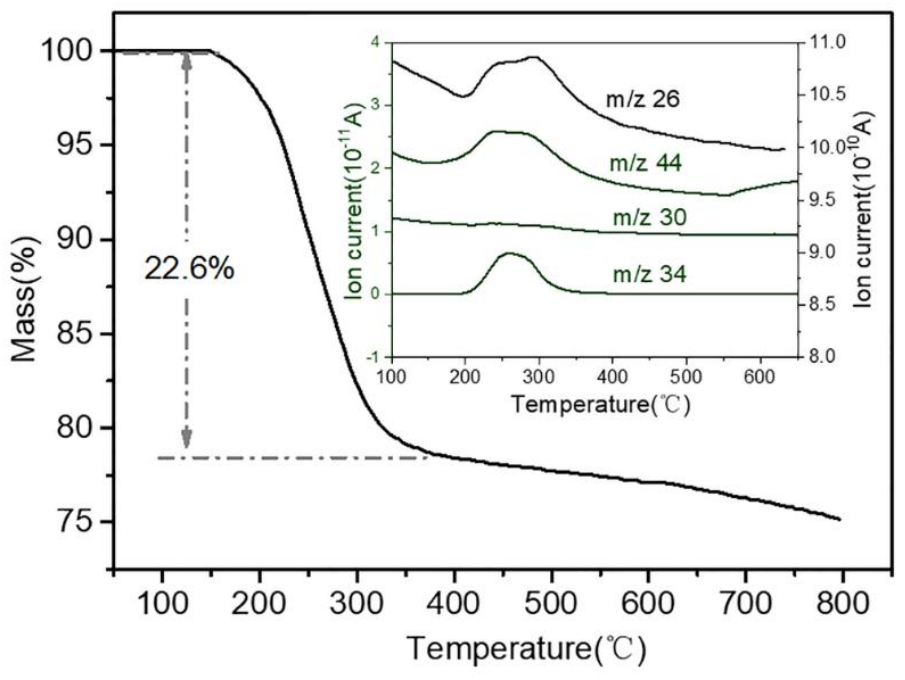

Figure 2. TG-MS analysis of $\mathrm{MoS}_{2}$ sample Solvo-IV-2. 


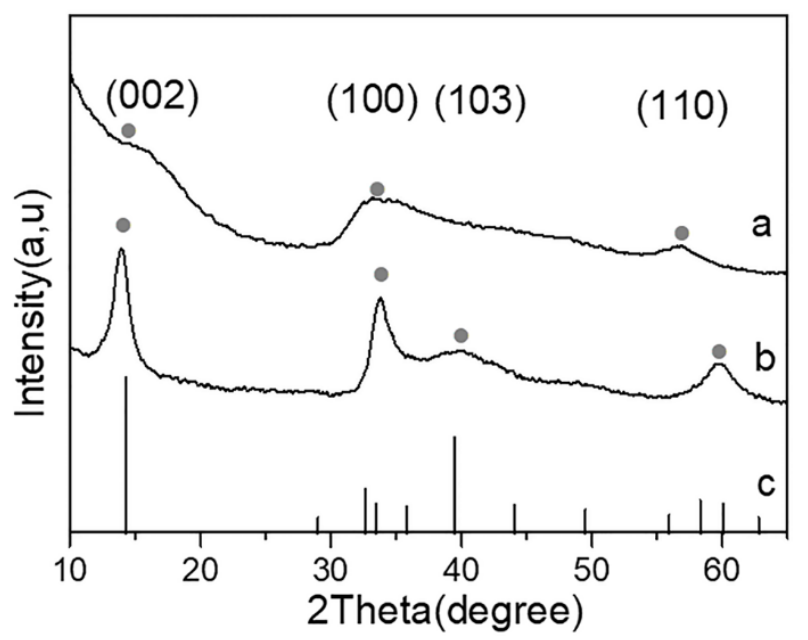

Figure 3. XRD patterns of $\mathrm{MoS}_{2}$ samples (a) Solvo-IV-2 and (b) Hydro-2, and (c) the sample represented by PDF \# 37-1492 card. 
1. (a)

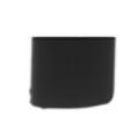

(b)

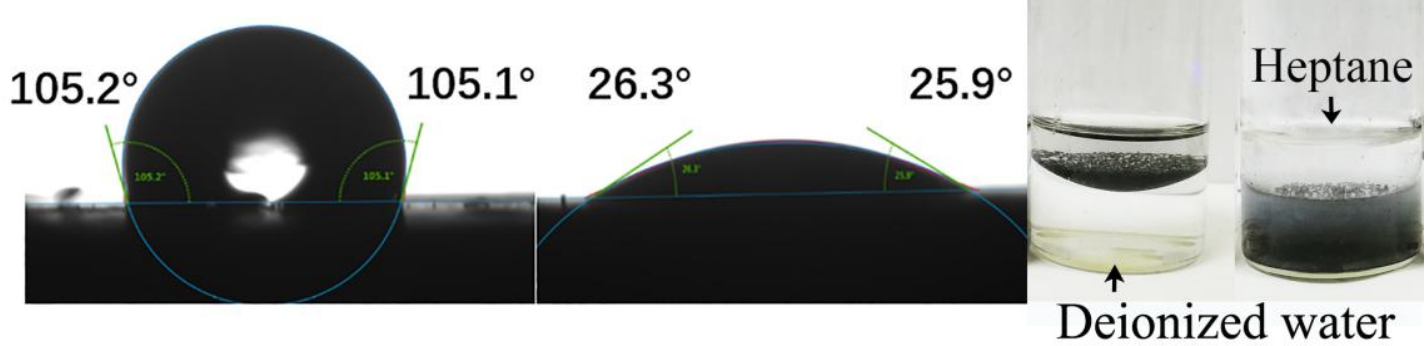

Figure 4. Air-water contact angle measurements of $\mathrm{MoS}_{2}$ Solvo-IV-2 (1.a) and Hydro-2 (1.b) samples; dispersion of sample Solvo-IV-2 in deionized water and heptane. 


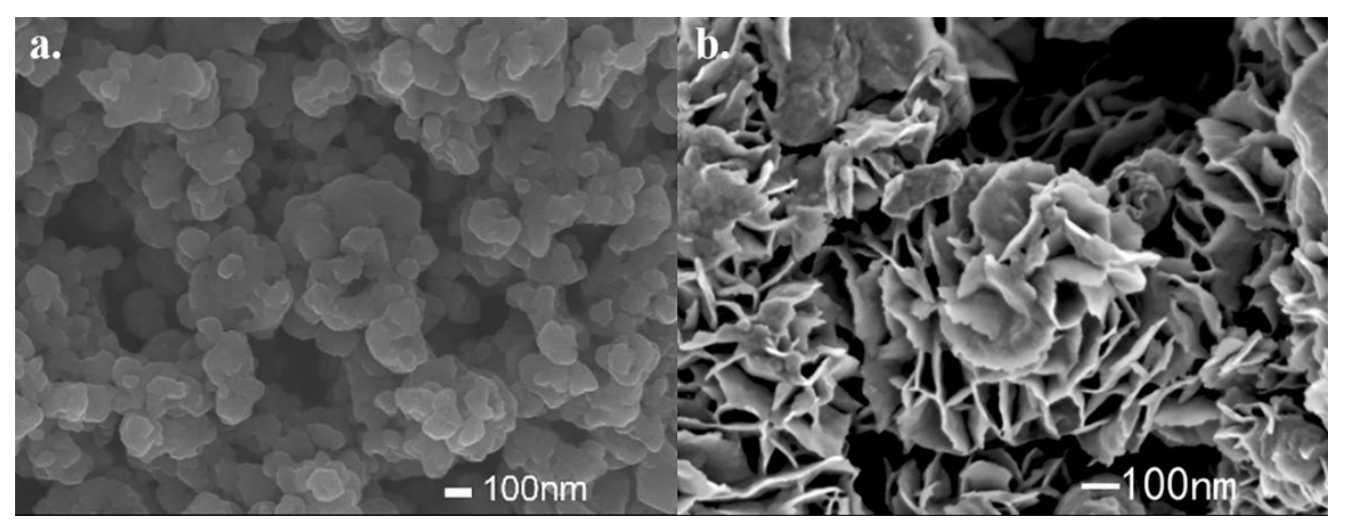

Figure 5. SEM pictures of $\mathrm{MoS}_{2}$ samples: (a) Solvo-IV-2, and (b) Hydro-2. 

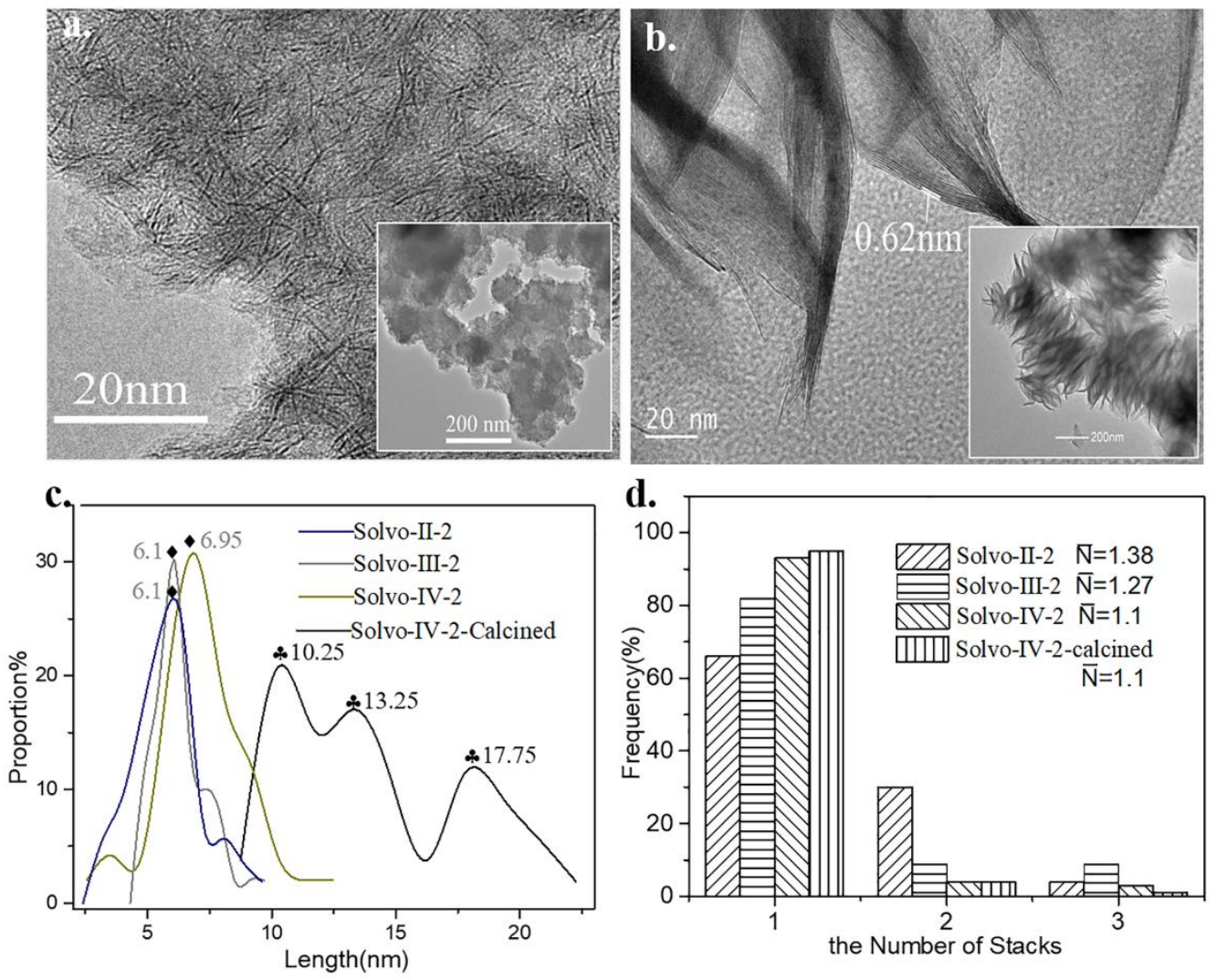

Figure 6. TEM pictures of $\mathrm{MoS}_{2}$ samples: (a) Solvo-IV-2, and (b) Hydro-2; (c) layer length and (d) stack number distribution of sample Solvo-IV-2. 


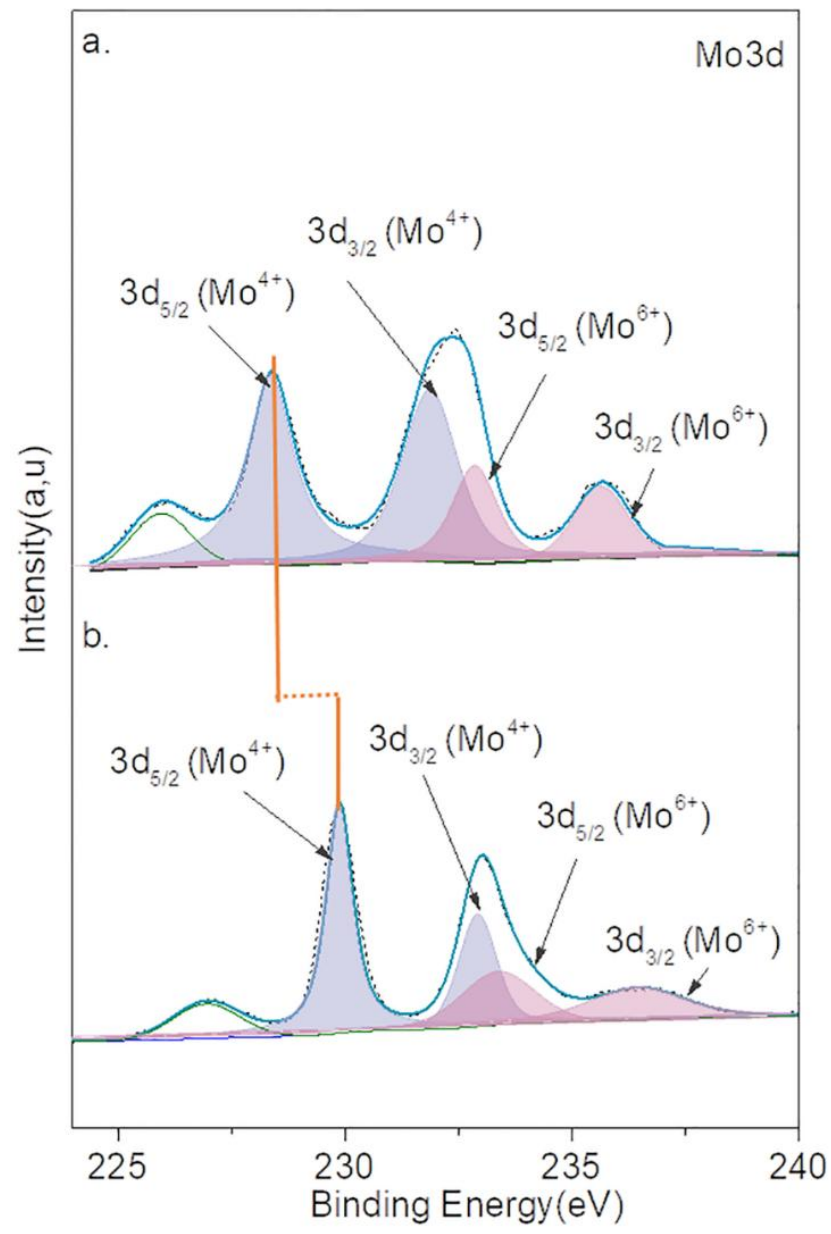

Figure 7. XPS spectra of $\mathrm{MoS}_{2}$ samples: (a) Solvo-IV-2, and (b) Hydro-2. 

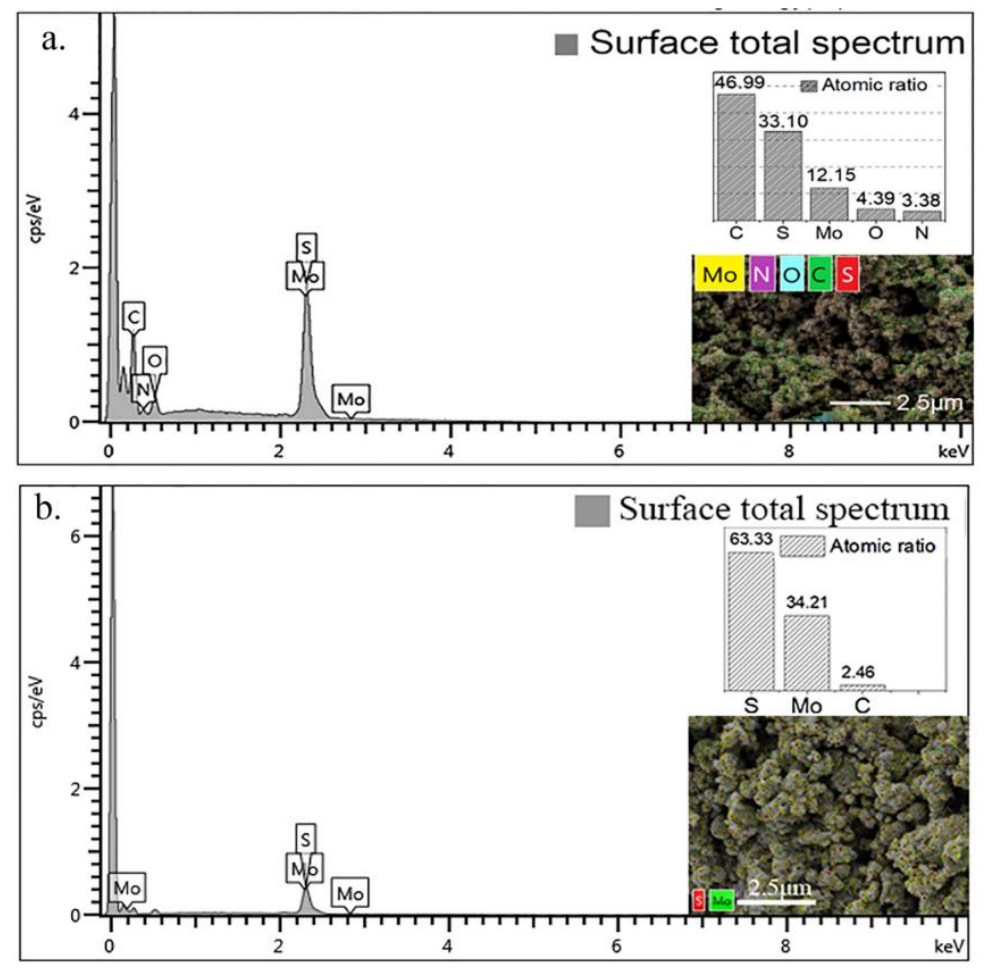

Figure 8. EDX spectra of $\mathrm{MoS}_{2}$ samples: (a) Solvo-IV-2, and (b) Hydro-2. 


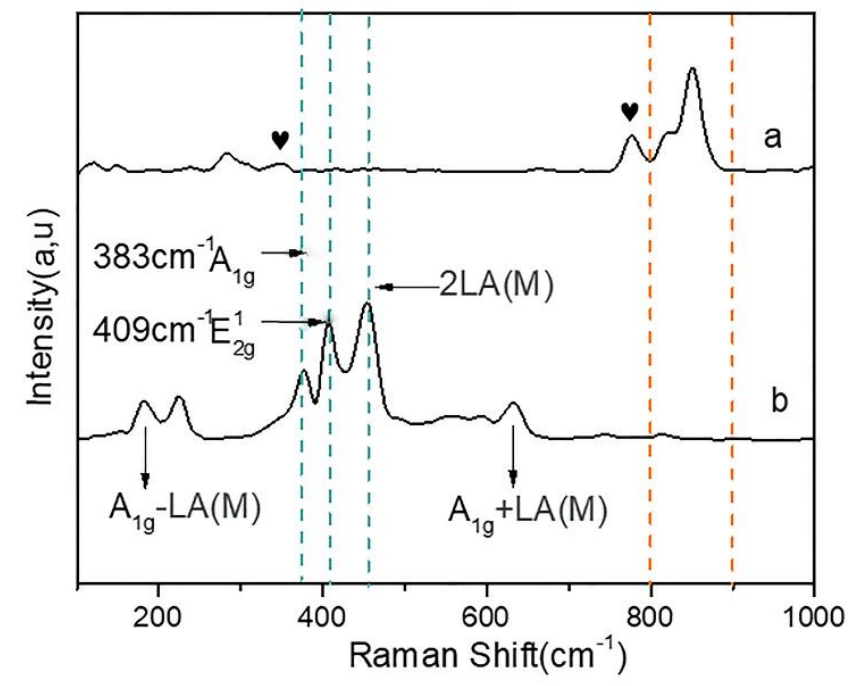

Figure 9. Raman spectra of $\mathrm{MoS}_{2}$ samples: (a) Solvo-IV-2, and (b) Hydro-2. 

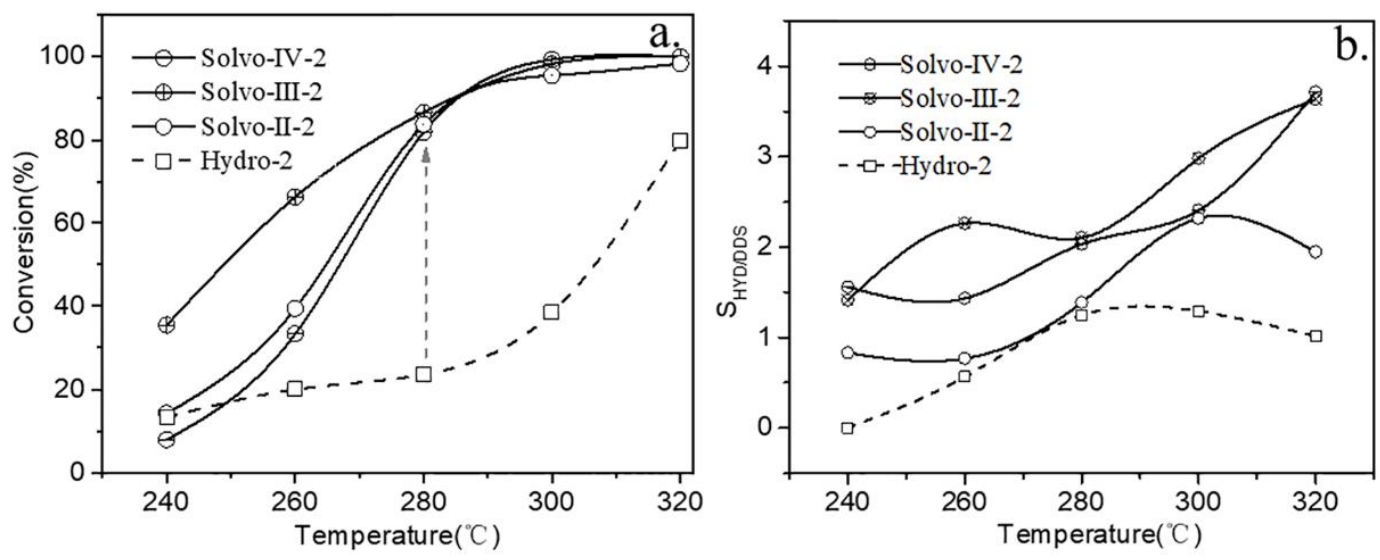

Figure 10. Conversion (a) and selectivity (b) of Solvo-series samples (Solvo-II-2, Solvo-III-2, and Solvo-IV-2) and Hydro-2 samples in DBT reaction. 

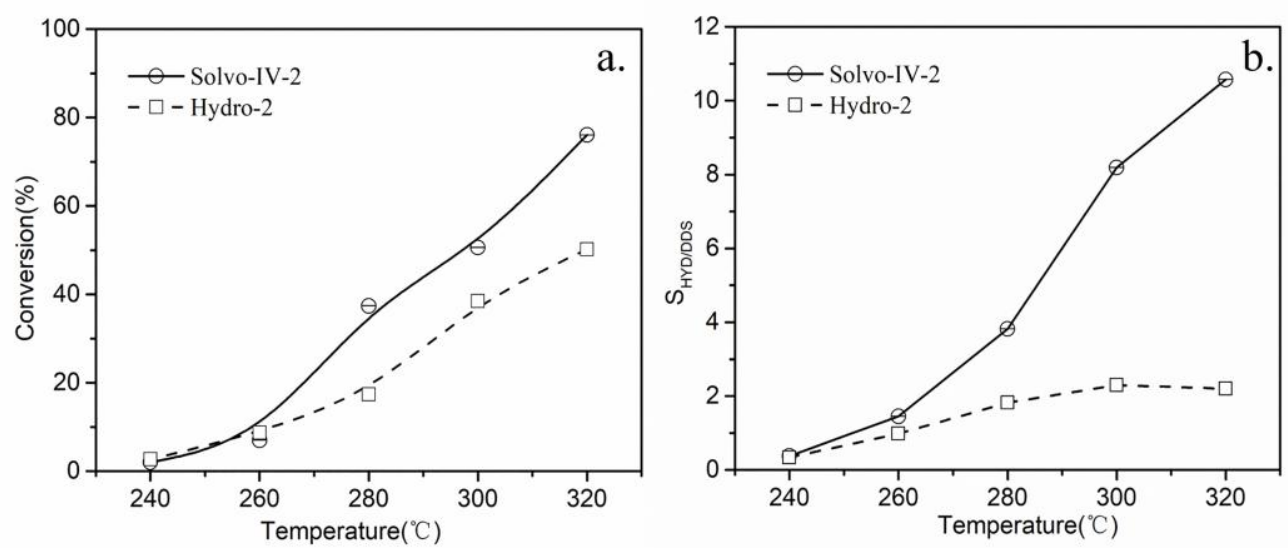

Figure 11. Conversion (a) and selectivity (b) of samples Solvo-IV-2 and Hydro-2 in 4, 6-DMDBT reaction. 


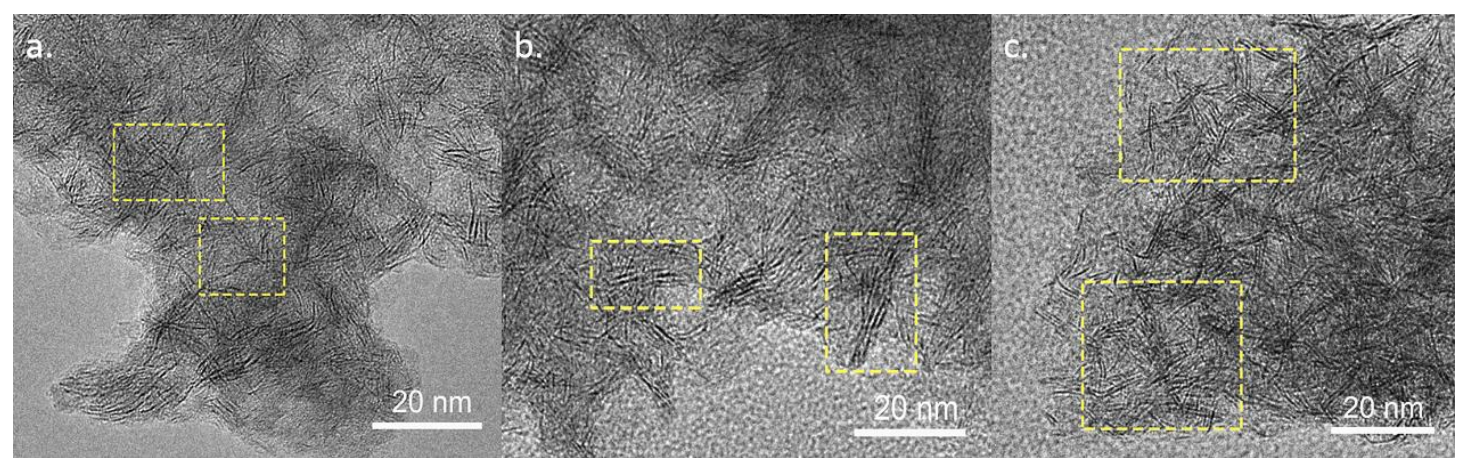

Figure 12. TEM pictures of $\mathrm{MoS}_{2}$ samples: a. Solvo-IV-2, b. Solvo-III-2, and c.Solvo-II-2. 


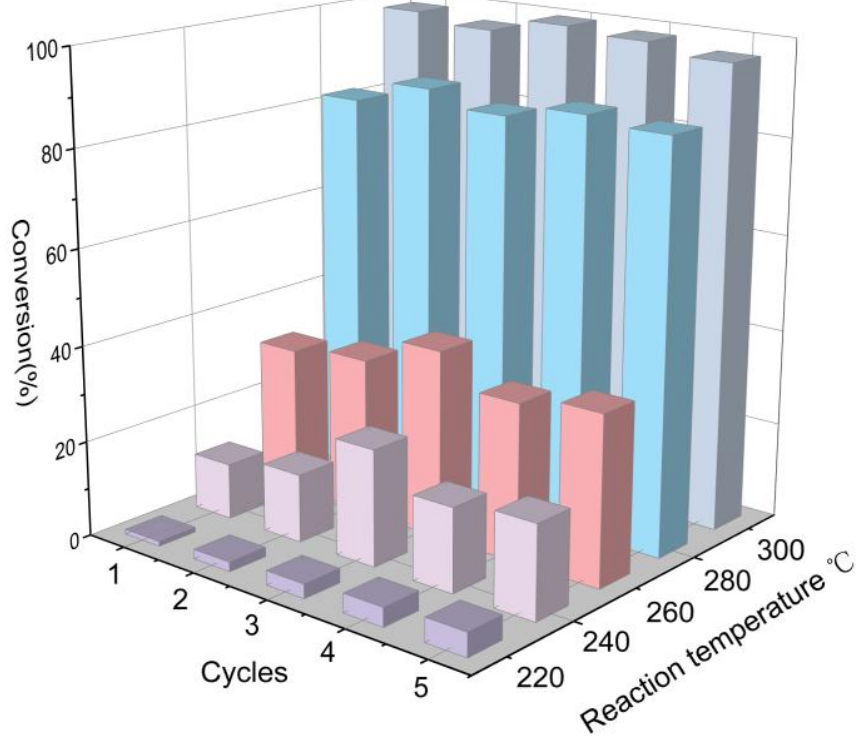

Figure 13. Conversion of DBT for 5 cycles at different temperatures $\left(220-300^{\circ} \mathrm{C}\right)$ of $\mathrm{MoS}_{2}$ sample Solvo-IV-2. 


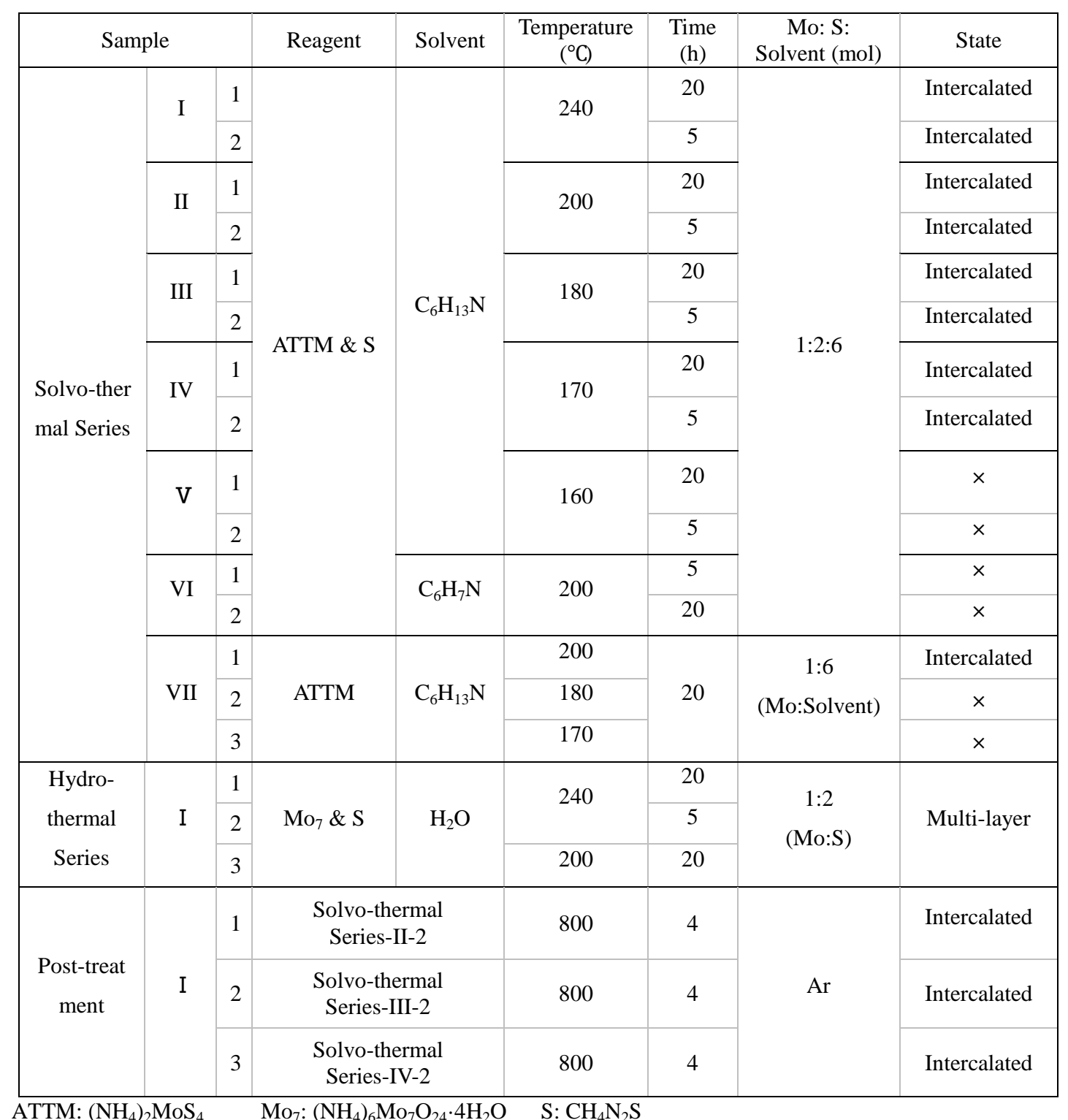

Table 1. List of samples prepared by under different preparation conditions. 


\begin{tabular}{|c|c|c|c|c|c|c|c|c|}
\hline Sample & \multicolumn{2}{|c|}{ Solvo-IV-2 } & \multicolumn{2}{|c|}{ Solvo-III-2 } & \multicolumn{2}{|c|}{ Solvo-II-2 } & \multicolumn{2}{|c|}{ Hydro-2 } \\
\hline $\begin{array}{l}\text { Active sites } \\
\text { dispersion } \\
\text { (D) }\end{array}$ & \multicolumn{2}{|c|}{0.206446} & \multicolumn{2}{|c|}{0.187487} & \multicolumn{2}{|c|}{0.175535} & \multicolumn{2}{|c|}{0.3118908} \\
\hline $\begin{array}{c}\text { Tem. } \\
\left({ }^{\circ} \mathrm{C}\right)\end{array}$ & & $\begin{array}{c}\text { TOF } \\
\left(10^{-3} \mathrm{~s}^{-1}\right)\end{array}$ & $\begin{array}{c}x \\
(\%) \\
\end{array}$ & $\begin{array}{c}\text { TOF } \\
\left(10^{-3} \mathrm{~s}^{-1}\right)\end{array}$ & $\begin{array}{c}x \\
(\%) \\
\end{array}$ & $\begin{array}{c}\text { TOF } \\
\left(10^{-3} \mathrm{~s}^{-1}\right)\end{array}$ & $\begin{array}{c}\mathrm{x} \\
(\%) \\
\end{array}$ & $\begin{array}{c}\text { TOF } \\
\left(10^{-3} \mathrm{~s}^{-1}\right)\end{array}$ \\
\hline 240 & 7.9 & 0.13 & 35.4 & 0.62 & 14.2 & 0.26 & 13.2 & 0.14 \\
\hline 260 & 33.3 & 0.55 & 66.2 & 1.17 & 39.4 & 0.72 & 20.0 & 0.22 \\
\hline
\end{tabular}

a Conversion of DBT HDS: $x$

Table 2.1 Conversion of DBT and TOF $\left(10^{-3} \mathrm{~s}^{-1}\right)$ of $\mathrm{MoS}_{2}$ catalysts.

\begin{tabular}{|c|c|c|c|c|c|c|c|c|}
\hline Sample & \multicolumn{2}{|c|}{ Solvo-IV-2 } & \multicolumn{2}{|c|}{ Solvo-III-2 } & \multicolumn{2}{|c|}{ Solvo-II-2 } & \multicolumn{2}{|c|}{ Hydro-2 } \\
\hline $\begin{array}{l}\text { Tem. } \\
\left({ }^{\circ} \mathrm{C}\right)\end{array}$ & $\begin{array}{l}\mathrm{x}^{\mathrm{a}} \\
(\%)\end{array}$ & $\mathrm{k}_{\mathrm{HDS}}^{\mathrm{b}}$ & $\begin{array}{c}\mathrm{x} \\
(\%)\end{array}$ & $\mathrm{k}_{\mathrm{HDS}}$ & $\begin{array}{c}\mathrm{x} \\
(\%)\end{array}$ & $\mathrm{k}_{\mathrm{HDS}}$ & $\begin{array}{c}\mathrm{x} \\
(\%)\end{array}$ & $\mathrm{k}_{\mathrm{HDS}}$ \\
\hline 240 & 7.9 & 0.14 & 35.4 & 0.71 & 14.2 & 0.25 & 13.2 & 0.11 \\
\hline 260 & 33.3 & 0.68 & 66.2 & 1.77 & 39.4 & 0.82 & 20.0 & 0.17 \\
\hline 280 & 81.8 & 2.88 & 86.6 & 3.29 & 79.7 & 2.63 & 23.5 & 0.21 \\
\hline 300 & 99.3 & 8.38 & 98.3 & 6.68 & 95.5 & 5.11 & 38.4 & 0.37 \\
\hline
\end{tabular}

a Conversion of DBT HDS: $\mathrm{x}$

b. $\mathrm{k}_{\mathrm{HDS}}: 10^{-3} \mathrm{~mol}^{-1} \mathrm{~h}^{-1}$

Table 2.2 Conversion of DBT and $\mathrm{K}_{\mathrm{HDS}}\left(10^{-3} \mathrm{~s}^{-1}\right)$ of $\mathrm{MoS}_{2}$ catalysts. 